\title{
The Economics of Sight and Vision Loss
}

Eighth Annual Lecture

Faculty of Ophthalmology, National Postgraduate Medical College, Nigeria

Delivered on the $5^{\text {th }}$ of August 2005

Hannah B. Faal

Consultant Ophthalmologist

Sight Savers International

$\mathrm{I}$

$t$ is a singular honour for me to be invited to give the eighth faculty lecture of the Faculty of Ophthalmology of the National Postgraduate Medical College of Nigeria.

When I was informed that the chairman of this occasion was to be the honourable minister of health, I was happy on the one hand and filled with trepidation on the other. Happy to meet him once again and share ideas, fearful to speak as a lay person on a topic touching on health economics in the presence of a health economist of international repute. To some extent I am relieved he is not here today. He will probably later read the lecture, but by then I will be miles away.

I am humbled and appreciative to have in the audience my teachers at the beginning of my career on ophthalmology, Professors Oyin Olurin and Bopo Osuntokun, and my first senior colleague as a consultant ophthalmologist, Professor J. Ayanru. Thank you for the nurturing.

Another teacher is Professor O.O. Ajayi, with whom we all share the grief of the loss of his dear wife who is being interred today. I am indebted to him for his leadership in the sister college, the West African College of Surgeons.

I have a confession to make. Though a member of the Faculty of Ophthalmology of the National Postgraduate Medical College, I have not been an active member. I hope I will be forgiven as I believe that my active involvement in and contributions to the Faculty of Ophthalmology of the sister college, the West African College of Surgeons has, like a stone thrown into a pond, sent ripples to the National Postgraduate Medical College.

It is with pleasure that I deliver this lecture on the Economics of Sight and Vision Loss - the 2005 Annual Lecture - at the College Auditorium of my alma mater, the University College Hospital, Ibadan.

I need to state that I am notorious for not keeping to time, the topic, being non-medical may be 'dry' and if anyone dozes, could the neighbour please nudge him/her awake. During the next hour, I will be addressing the following questions and issues:

1. Why did I choose the topic?

2. What is known about the economic impact of sight and vision loss?

3. What is the cost benefit of investing in sight?
4. To invest or not to invest in the irreversibly visually disabled?

\section{Quo vadis?}

The first question on why I choose a topic on economics I have examined from the following aspects.

\section{Why Economics?}

- 'Funding'

- Millennium Development Goal (MDGs)

- Poverty reduction

- The New Partnership for Africa's Development (NEPAD) and its health strategy

- Commission for Africa

- Health and development

The word 'funding', a term commonly used to mean a problem which, if solved?, is a 'cure-all' solution. During my many visits to Nigeria, in my interactions with colleagues, health providers in general, and patients, 'funding' is the most frequently quoted constraint. Activities, projects minor and major - cannot be initiated or continued because of lack of 'funding'! Give us the funding"; they say or if only we have the 'funding'.

Often, while reading a Nigerian newspaper or watching television, I am constantly amazed at the number of 'launchings' of one infrastructure or the other, or one initiative or another which was going to cost millions and billions of naira. The funding was the most proclaimed. It was obvious that funding was often generously available for that one off event. Often I wondered about the post launch period, the post-event period. Did the event proceed to a vibrant living activity which delivered on its hope and promises over a long time? A specific worrying example was the trend of cataract camps where millions of naira were often spent. What is the mathematics of the unit cost of one cataract surgery done at the camp? How does that unit cost compare with the unit cost of cataract surgery done in a hospital? What happened in the post-event period after the 'sound and fury'? What indeed has been the opportunity cost of the 'event'? What was left undone and unpaid for because of the event? Is there any analysis, review, or reporting on the cost benefit of the 'event'? Before the launch of any event takes place, there is a decision making process; 
what factors guide the 'funding' allocation, release and expenditure.

The second reason I chose the topic, had to do with the Millennium Development Goals (MDGs) and poverty reduction and the linkage between health and development; all of which are enmeshed within the fabric of economics. African heads of state have responded to the Millennium Development Goals and formed The New Partnership for Africa's Development (NEPAD), which has in fact formulated a health strategy.

The United Nations Millennium Summit of September 2000 set goals to be achieved by the year 2015; 5 years have gone by, only 10 more to go.

The Millennium Development Goals (MDGs) as they were termed are:

1. Eradicate extreme poverty and hunger

2. Achieve universal primary education

3. Promote gender equality and empower women

4. Reduce child mortality

5. Improve maternal health

6. Combat HIV / AIDS, malaria and other diseases

7. Ensure environmental sustainability

8. Develop a global partnership for development

Three out of the eight goals are explicitly health goals but every one of the other five goals have an inextricable relationship with health. Health is linked to disease, disability and death. Health sits at the core of development and poverty reduction and needs to be seen within such a context. This is exemplified by the table of comprehensive services below.

Table 1. Comprehensive eye services

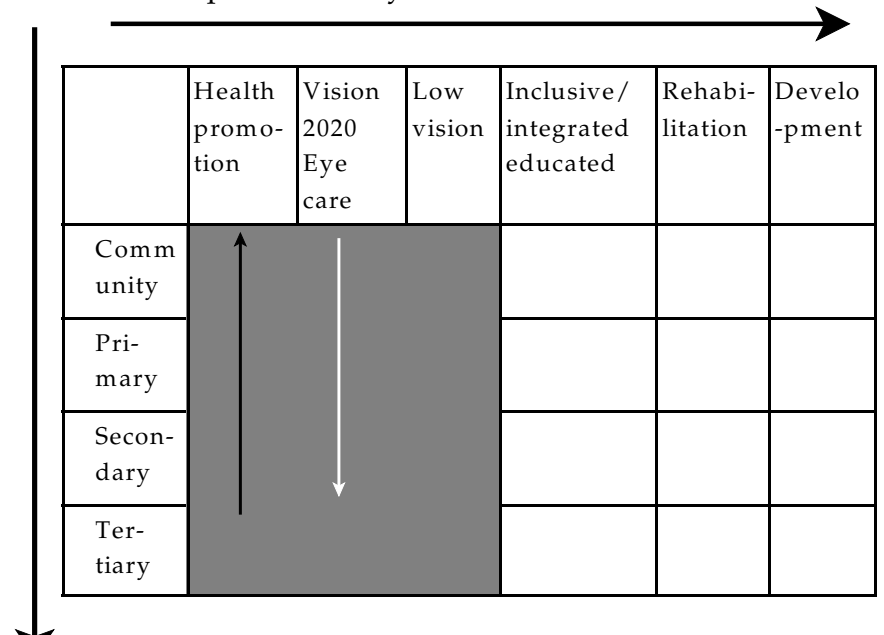

In providing comprehensive eye services, the services range seamlessly from health promotion to eye care, to enhancement of residual low vision, to integrated education of blind and low vision children, to rehabilitation of the blind adult. The services offered at each level run from the community straight through to the tertiary level. Each service at each level contributes to development and poverty reduction by prevention of disease, disability and death and by reducing the impact of disability.

When one looks at a map of Africa which shows gross domestic product, there is a band of pallor across subSaharan Africa with the countries with higher gross domestic products being in the northern and southern tips( figure 1). It reminds one of the song: the Lighter Shade of Pale.

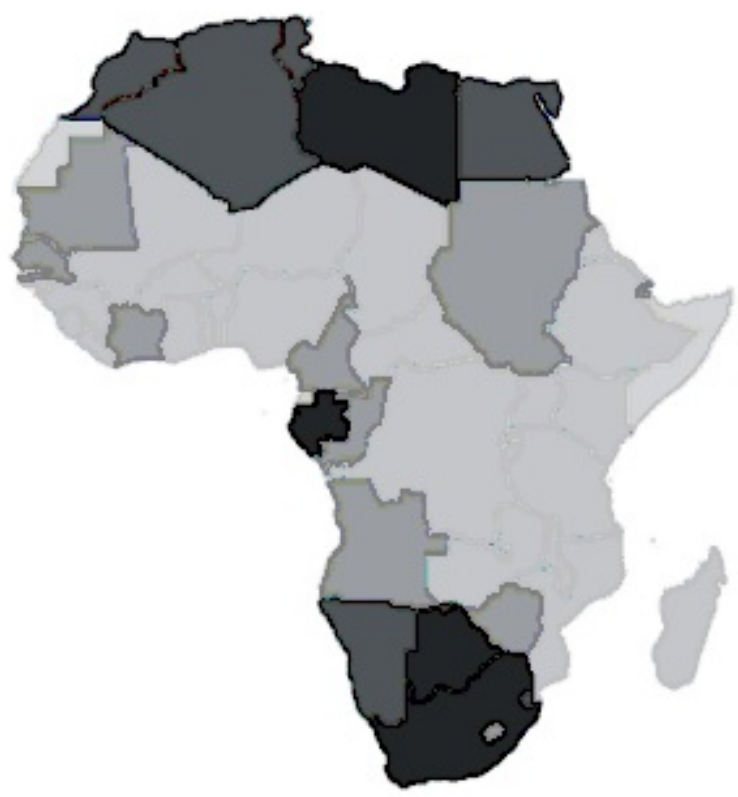

Figure 1. Map of Africa showing gross domestic product of countries. Note lighter shade across sub-Saharan countries

\section{THE NEW PARTNERSHIP FOR AFRICA'S DEVELOPMENT (NEPAD)}

African heads of state have responded to the millennium development goals and the sub-Saharan pallor by forming the New Partnership for Africa's Development - NEPAD, which has also formulated a health strategy. NEPAD recognized that in Africa, health has become a casualty of poverty, social exclusion, marginalization and lack of sustainable development. This has constituted a block to economic development and thus it was highly unlikely that Africa would be on target to achieve the health-related MDGs. A NEPAD health strategy was formulated in 2002/3, which positioned health firmly within the framework of reforms of systems and sectors which have direct and/or indirect effects on health delivery.

Moving away from Africa to the United Nations, J. Sachs, the UN Adviser to Kofi Annan on the MDGs, in an article in The Economist of May 2004, linked health in some ways to poverty reduction: "An ounce of prevention is worth a ton of treatment". He felt that poverty, hunger and disease leave Africa vulnerable to security and natural disasters and so it was in the interest of the developed world to prevent poverty, hunger and disease thus averting insecurity, conflict, crises, and disaster which end up being a lot more 
expensive to deal with. The amount of money required has always proven to be smaller if the developed world invests in prevention rather than wait for disasters, which not only prove more expensive but usually involve huge loss of lives and untold suffering. A typical example was the AIDs pandemic.

The UN adviser went on to make a practical proposal similar to the post-war plan used in Europe after World War II and now Afghanistan and Iraq. Essentially, it was to carry out a basic needs assessment and a calculation of the resources required to reverse the downward trend in development in Africa. When he got no response, his unit conducted a mini assessment covering a few countries, looking at basic infrastructure, social service provision, human resources, etc. His conclusion was that what was required was US\$100 per person per year composed of:

- Basic infrastructure, water, power - $\$ 45$

- $\quad$ Basic health care $-\$ 30$

- Upgrading primary and secondary education - \$15

- Others $-\$ 10$

Of the US\$100 required, US\$40.00 was already available from national resources and US\$10.00 is being provided as aid. The extra resource to be mobilized was just US $\$ 50$ per person per year.

He decried the link of aid to good governance when the same rule was not applied to Afghanistan and Iraq. There was a lack of encouragement to sub-Saharan countries genuinely making major strides in good governance and self reliance.

The world has not been entirely quiet. There is the ongoing campaign titled, 'Make Poverty History', using a white wristband worn by all supporters. The British prime minister, Tony Blair, has set up the Commission for Africa, and pushed the G8 countries for debt relief/cancellation.

There has been a hue and cry for trade justice. The results have been less than desirable but a short small step has been taken.

What is happening in Nigeria? President Olusegun Obasanjo got the famous 'Paris relief', but what is the civil society in Nigeria doing to 'make poverty history'?

I go back to why I chose a topic on economics. Health is not just the mere absence of disease, but a state of physical, mental and social well-being - WHO definition. Well-being is development and development is also about economics. Therefore, health workers are development agents and thus agents of change. And as Mahatma Ghandi said:

Each of us should be the change we want to see in the world.

In vision, a change has taken place; a global campaign.

It is called VISION 2020 - The Right to Sight. It aims to 'eliminate avoidable blindness and low vision by the year 2020 ' and is a global concerted effort spearheaded by a global partnership of all stakeholders in vision.

Launched in 1999 by the director general of WHO, its main strategy components are: disease control, human resource development and the provision of infrastructure and technology, with the support strategies of advocacy, resource mobilization, management and community participation. VISION 2020 - The Right to Sight exemplifies the intent of the MDGs; it deals with disease, reduction of disability, and addresses sight as a human right, all within an action-oriented time-bound initiative.

In recognition of the wider dimensions of health, the Vision 2020 partnership - WHO and the International Agency for the Prevention of Blindness - explored the economic impact of Vision 2020. Using economic and epidemiologic modelling, some of the issues examined were the global population changes in absolute numbers and by age group bands, the prevalence of blindness, economic productivity loss and the number of years of life gained without and with vision 2020 from the year 2000 to 2020. The work was done by Professor A. Foster of the International Centre for Eye Health, London and Professor Kevin Frick of Johns Hopkins Bloomberg School of Public Health, Baltimore. The study estimated that the global population will increase from 6850 million to 7317 million. In subSaharan Africa this increase would be from 659 million to 978 million in 2020 with an increase of 5 million persons in the age group most affected by vision loss, i.e. 65 years and above, every 10 years. An increase in global population by about 1.4 billion.

Table 2. Population estimates by World Development Region

\begin{tabular}{|c|c|c|c|c|c|c|c|c|c|c|c|c|}
\hline \multirow{2}{*}{$\begin{array}{l}\text { World Development } \\
\text { Region }\end{array}$} & \multicolumn{4}{|c|}{2000} & \multicolumn{4}{|c|}{2010} & \multicolumn{4}{|c|}{2020} \\
\hline & Pop. (m) & $0-14$ & $15-64$ & $65+$ & Pop. (m) & $0-14$ & $15-64$ & $65+$ & Pop. (m) & $0-14$ & $15-64$ & $65+$ \\
\hline China & 1,262 & 25 & 68 & 7 & 1,359 & 21 & 71 & 8 & 1,434 & 19 & 70 & 12 \\
\hline Established market economies & 850 & 18 & 67 & 15 & 888 & 17 & 66 & 17 & 914 & 16 & 64 & 20 \\
\hline Former socialist economies & 325 & 18 & 69 & 13 & 327 & 16 & 71 & 14 & 320 & 16 & 67 & 17 \\
\hline India & 1,014 & 34 & 62 & 5 & 1,168 & 29 & 66 & 5 & 1,312 & 26 & 67 & 7 \\
\hline Latin America/Caribbean & 520 & 32 & 63 & 5 & 586 & 27 & 66 & 7 & 645 & 24 & 67 & 9 \\
\hline Mid-Eastern Crescent & 622 & 37 & 59 & 4 & 742 & 32 & 64 & 5 & 868 & 29 & 65 & 6 \\
\hline Other Asian Islands & 818 & 31 & 64 & 5 & 939 & 28 & 66 & 6 & 1,046 & 24 & 68 & 8 \\
\hline Sub-Saharan Africa & 659 & 44 & 53 & 3 & 814 & 42 & 55 & 3 & 978 & 40 & 57 & 3 \\
\hline Global & 6080 & 30 & 63 & 7 & 6,823 & 27 & 66 & 8 & 7,517 & 25 & 66 & 9 \\
\hline
\end{tabular}


Table 3. Estimated prevalence of blindness by World Development Region (\%)

\begin{tabular}{|c|c|c|c|c|c|}
\hline \multirow[b]{2}{*}{ World Development Region } & \multirow[b]{2}{*}{2000} & \multicolumn{2}{|c|}{2010} & \multicolumn{2}{|c|}{2020} \\
\hline & & $\begin{array}{c}\text { Without } \\
\text { VISION } 2020\end{array}$ & $\begin{array}{c}\text { With } \\
\text { VISION } 2020\end{array}$ & $\begin{array}{c}\text { Without } \\
\text { VISION } 2020\end{array}$ & $\begin{array}{c}\text { With } \\
\text { VISION } 2020\end{array}$ \\
\hline China & 0.60 & 0.74 & 0.51 & 0.95 & 0.33 \\
\hline Established market economies & 0.30 & 0.34 & 0.32 & 0.38 & 0.28 \\
\hline Former socialist economies & 0.30 & 0.34 & 0.32 & 0.37 & 0.27 \\
\hline India & 1.00 & 1.15 & 0.80 & 1.37 & 0.33 \\
\hline Latin America/Caribbean & 0.50 & 0.60 & 0.50 & 0.74 & 0.28 \\
\hline Mid-Eastern Crescent & 0.70 & 0.79 & 0.62 & 0.94 & 0.33 \\
\hline Other Asian Islands & 0.80 & 0.96 & 0.63 & 1.19 & 0.35 \\
\hline Sub-Saharan Africa & 1.40 & 1.43 & 0.83 & 1.50 & 0.38 \\
\hline Global & 0.72 & 0.85 & 0.59 & 1.01 & 0.33 \\
\hline
\end{tabular}

The prevalence of blindness rate without vision 2020 would increase from $0.72 \%$ in the year 2000 to $1.01 \%$ in the year 2020. Vision 2020 could ensure a drop to $0.33 \%$ in 2020 , a reduction of $70 \%$ over the 20 -year period.

The number of blind persons would increase from 44 million in the year 2000 to 76 million in 2020. Vision 2020 would result in only 24 million blind persons from causes which could not be prevented or cured. These points are more graphically illustrated in figures 1 and 2 . The impact of vision 2020 is estimated to result in 100 million people in whom blindness has been avoided and 429 million blind-person years avoided.

How does this translate in economic terms? A conservative estimate of economic loss in productivity over the 20 years was US $\$ 102$ billion for blind persons and US $\$ 121$ billion for persons with low vision. If on the other hand, looking at the less conservative estimate, i.e. added to this the factor that $10 \%$ of a sighted person's productivity is lost because he/she is caring for one blind person and that even if sighted, persons 65 years and above are half as productive as younger persons, then the estimated economic loss increases even further to a total of US\$ 310 billion, made up of US $\$ 151$ billion for blindness and US $\$ 159$ billion for low vision.

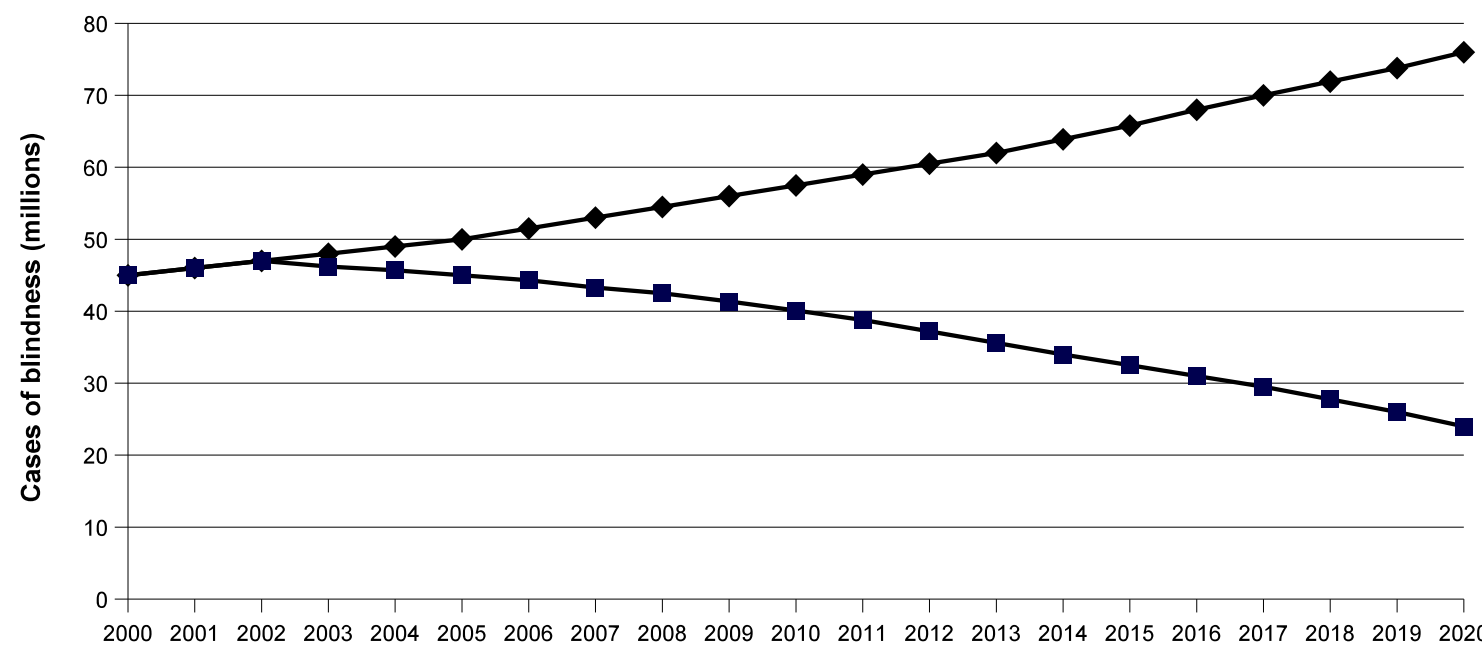

Year
Number of cases of blindness without Vision 2020

Number of cases of blindness with Vision 2020

Figure 1. Number of cases of blindness for all ages with and without VISION 2020. 
The Economics of Sight and Vision Loss

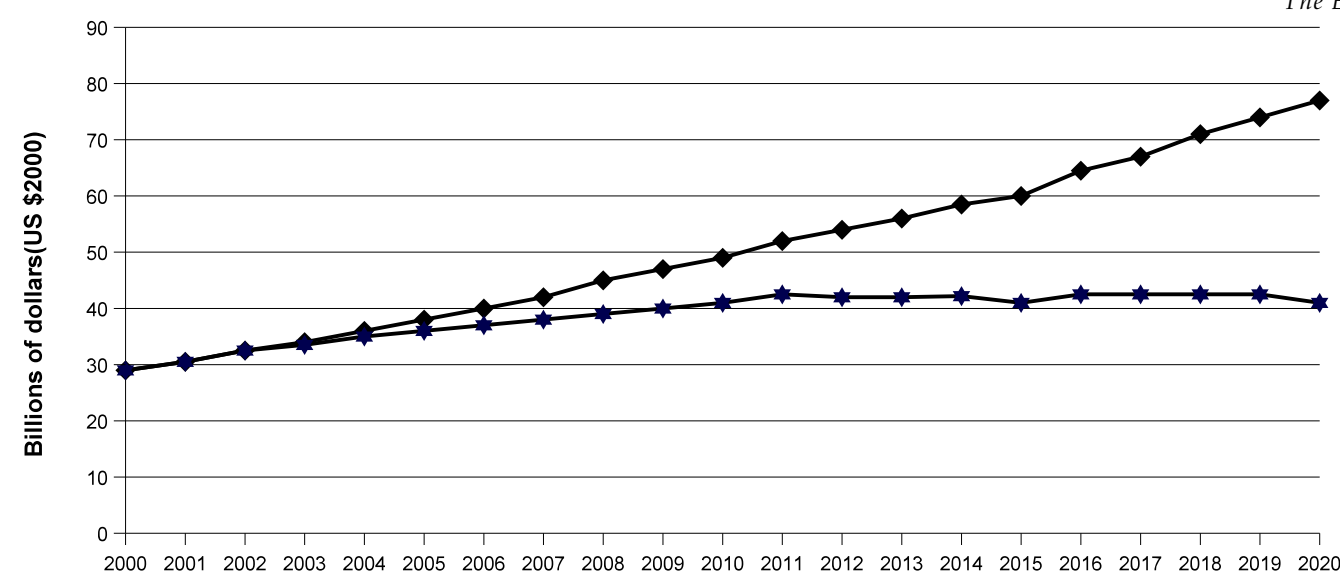

Economic productivity loss without Vision 2020

Economic

productivity loss with Vision 2020

Year

Figure 2. Annual economic

productivity loss due to blindness for all age groups and including informal care with or without Vision 2020.

Table 4. Less conservative estimate of economic loss in productivity

\begin{tabular}{|c|c|c|c|c|}
\hline Blind & $\$ 29$ billion & $\$ 77$ billion & $\$ 41$ billion & $\$ 151$ billion \\
\hline $\begin{array}{l}\text { Low } \\
\text { vision }\end{array}$ & $\$ 30$ billion & $\$ 80$ billion & $\$ 43$ billion & \$159 billion \\
\hline Total & $\$ 59$ billion & 157 billion & $\$ 84$ billion & $\$ 310$ billion \\
\hline
\end{tabular}

Coming nearer home to sub-Saharan Africa, it was estimated that the annual GDP loss due to blindness in the year 2000 was US $\$ 1830$ million equivalent to $0.46 \%$ of the regional GDP. Without vision 2020, this will rise to US\$4374 million or $0.50 \%$ of the GDP. With vision 2020 , it will fall to US $\$ 1123$ million equivalent to $0.13 \%$. An average calculated savings of US\$10 million population.

Table 5. GDP Loss in Sub-Saharan Africa due to Blindness

\begin{tabular}{lccc} 
& Year 2000 & $\begin{array}{l}\text { Without } \\
\text { Vision } 2020\end{array}$ & $\begin{array}{l}\text { With Vision } \\
2020\end{array}$ \\
\hline Amount & US\$1830 m & US\$4374m & US\$1123m \\
\hline $\begin{array}{l}\text { \% of regional } \\
\text { GDP }\end{array}$ & $0.46 \%$ & $0.50 \%$ & $0.13 \%$ \\
\hline
\end{tabular}

The question was posed: Can any evidence be found in a practical programmatic situation? A cost benefit analysis study was carried out. The Gambia implemented a national eye care programme over a 10-year period, 1986-1996, whose activities mirrored the vision 2020 strategies. Information was collected on all the inputs (cost) to the programme over the period. Fortunately, good records were kept and this highlights the importance of collecting information on all the inputs into a programme in cash or in kind and estimating this in economic terms in order to get the true cost of an intervention or a programme. For those embarking on new programmes, I would recommend that this is done prospectively because it can be hard and tedious to do this retrospectively.

Table 6. Total cost of all inputs by all partners over the 10 year period

\begin{tabular}{|c|c|c|}
\hline $\begin{array}{c}\text { Government } \\
25 \%\end{array}$ & $\begin{array}{c}\text { Sight Savers International } \\
74 \%\end{array}$ & $\begin{array}{c}\text { Others } \\
<1 \%\end{array}$ \\
\hline Salaries of personnel & $\begin{array}{l}\text { Eye units renovation and } \\
\text { construction }\end{array}$ & $\begin{array}{l}\text { Cataract } \\
\text { camp }\end{array}$ \\
\hline Accommodation & Ophthalmic/other equipment & $\begin{array}{l}\text { Used } \\
\text { spectacles }\end{array}$ \\
\hline $\begin{array}{l}\text { Drug supplies and } \\
\text { materials }\end{array}$ & $\begin{array}{l}\text { Human resource } \\
\text { development at all levels }\end{array}$ & \\
\hline Water and electricity & $\begin{array}{l}\text { Drug supplies and other } \\
\text { materials }\end{array}$ & \\
\hline $\begin{array}{l}\text { Telecommunica- } \\
\text { tions }\end{array}$ & $\begin{array}{l}\text { Vehicles, motorcycles and } \\
\text { some running costs }\end{array}$ & \\
\hline Transport costs & $\begin{array}{l}\text { Some salaries/benefits / } \\
\text { allow ances }\end{array}$ & \\
\hline \multicolumn{3}{|l|}{$\begin{array}{l}\text { Equipment } \\
\text { maintenance }\end{array}$} \\
\hline \multicolumn{3}{|l|}{ Patient feeding } \\
\hline Land & & \\
\hline
\end{tabular}

Government input was $25 \%$ of the total. It must be emphasized that in 1986, when this programme started, The Gambia was third from the bottom in the global economic 
ranking of countries. It had just undergone a structural adjustment programme and $30 \%$ of the civil service work force had been laid off. In spite of this, the government, which had committed itself to the Alma Ata Primary Health Care Strategy, took on a national eye care programme, starting with only what it had as existing resources. The non government organization, Sight Savers International, provided what the country could not, i.e. the capitalintensive costs of buildings, equipment, vehicles, and external training. The government met to a large measure, the recurrent costs.

\section{What was the benefit?}

The prevalence of blindness was estimated at the beginning of the programme in 1986 and after 10 years in 1996.

- There was a $40 \%$ reduction in the blindness prevalence rate from $0.7 \%$ to $0.4 \%$.

- The impact on people was that blindness was averted in 1658 persons.

- $\quad 320,000$ people with eye disease were treated.

- In economic terms, the benefit of the programme was US\$4.5 million

The internal rate of return (a term used by economists) to measure the net lifetime benefit was US $\$ 1,007$ million dollars, which yields an internal rate of return of $10 \%$. If similar benefits were allocated to Senegalese citizens who made up $30 \%$ of the patients, the internal rate of return could increase to $19 \%$ and if it is estimated that blind individuals lose $100 \%$ of their productivity, the internal rate of return would be over $20 \%$. In summary, if US $\$ 1.5$ million was spent, the total benefit would be US $\$ 4.5$ million and the net benefit, US\$2.9 million.

It is evident how this relates directly to poverty reduction, the elimination of avoidable causes of visual disability, and the development of a people. What of the NEPAD health strategy, placing health at the centre of all other issues that are inextricable linked to it? Did this programme address those factors? Let us use the leading cause of blindness - cataract - as an example.

Cataract blindness reduced by $50 \%$. The personnel who could perform the cataract surgery to restore sight increased from 1 to 6 ; the travel distance by patients to surgery facilities reduced from 500 kilometers to 60 kilometers, the number of hospital beds for eye patients increased from 7 to 63 and the number of cataract operations per million population increased by $500 \%$ from 300 to 1500 . All aspects of the health delivery structure and systems were positively affected and they had to be to get such positive results

It was not possible to put an economic stamp on all areas of benefits. The benefits that could not be measured were the improvement in the quality of life of the patients and their families; the benefits to the health providers from the capacity building, job satisfaction, etc; the benefits to non Gambians who made up $30 \%$ of the patients; the benefit from improved infrastructure nor the knock on catalytic positive effects The Gambia national eye care programme has had on other programmes within and outside the country.

We have so far examined the economic impact of disability-blindness, the cost of providing services, the benefit derived from the provision of these services cost/benefit analysis.

What are the causes of visual disability? Globally $75-80 \%$ of these causes can be prevented or cured; they are totally avoidable. They include:

- Cataract

- Trachoma

- Onchocerciasis

- Childhood blindness

- Uncorrected refractive errors and unenhanced low vision

- Glaucoma

- Diabetic retinopathy

Cataract, a clouding of the natural lens inside the eye mainly due to old age, is the leading cause of blindness/visual disability the world over.

Trachoma and onchocerciasis are focal diseases confined mainly now to Africa. Trachoma is associated with poverty, arid areas with poor water supply and sanitation, while onchocerciasis - river blindness - is transmitted by the black fly - Simulium damnosum.

Childhood blindness is an indicator of poverty due to infections and Vitamin A deficiency. Half of blind children die before the age of 2 years, those who survive live many more years with the disability than the aged who have cataract.

Refractive errors and low vision. The world underestimates the number of people who cope with poor vision for distance or for close-up work and suffer for lack of a simple pair of glasses; and the children who do not perform well at school for the same reason.

Glaucoma. It is estimated that worldwide 8 million people are blind from glaucoma - irreversible loss of vision due mainly to increased pressure inside the eyeball. For those 8 million, medical care can no longer do anything to restore their sight, they will need to be rehabilitated; that will be discussed later. There are, however, another 50 million people living with the disease who mostly need lifetime treatment with eye drops and or surgery. Only glaucoma patients and/or their families can explain the cost and suffering caused by the disease. Tragically, over half of those who have the condition are unaware that they have it.

Diabetes retinopathy. The world is noticing a quiet epidemic - diabetes mellitus, 'the sugar disease'. The numbers are growing exponentially, and with it eye complications. Unfortunately, it is becoming a major cause of blindness. 
Cataract, the leading cause of sight loss can be restored by surgery. The World Bank classes cataract surgery as a 'cost-effective intervention' alongside measles vaccination.

Trachoma is an entirely preventable disease. In Nigeria, river blindness control is a success story with the distribution of mectizan. Childhood blindness can almost be entirely eliminated with successful immunization and vitamin A supplementation programmes, and refractive errors can easily be corrected with glasses. The emerging causes, glaucoma and diabetic retinopathy are also being tackled by public health approaches. The overall message is that many of the cases of blindness are needless; the cost of avoiding blindness is minimal, and the benefit is maximal.

\section{WHAT OF SUB SAHARAN AFRICA?}

Unfortunately in sub-Saharan Africa, we are still faced with these largely avoidable causes.

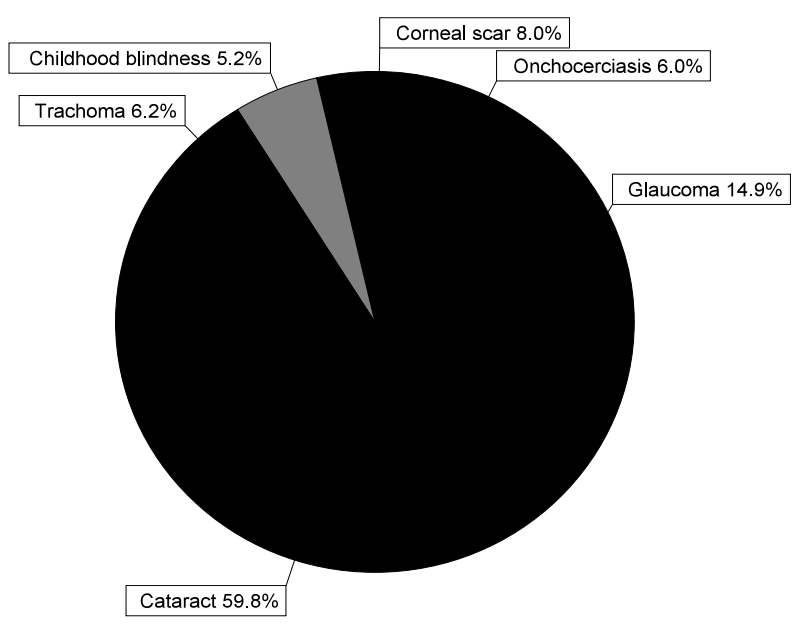

Figure 3. Causes of visual disability in Africa

Australia, a developed country with groups of populations in similar health situations as the developing world, has fully adopted the vision 2020 strategy and has undertaken a comprehensive review of the problem, the economic impact, the cost of vision disorders, the cost of interventions, the benefit of interventions and the benfit of investing in sight. Much of what is presented here are the results of that review published in Clear Insight - the Economic Impact and Cost of Vision in Australia and Investing in Sight - Strategic Interventions to Prevent Vision Loss in Australia' by the Centre for Eye Research, Australia, 2004.

Costs of vision disorder were estimated under 3 headings:

1. Direct costs of prevention and treatment

2. Indirect costs

3. Cost of suffering and premature death

Direct costs include the costs of prevention and treatment of all vision disorders in hospital, out of hospital, and other health costs.
Indirect costs include the cost to carers and the lost productivity of the adults, the lost education of the child and its lost productivity later as an adult. There is also a cost to the aids, and the home modification made to cater for the blind person.

We are all familiar with the scene of the young sighted child leading the blind adult around. Some people quip that the blind beggar makes a lot of money from begging. What we must remember is that for one beggar who makes money from begging, there are hundreds more tucked away in homes not earning any income. Also, what about the lost income of the blind person because of his disability?

Not easily quantifiable is the cost of suffering and premature death. Blindness and cancer are the two most feared conditions; one is a disability, the other kills. Though seen as a disability, it is estimated that $1 \%$ of premature deaths are attributable to blindness. The socioeconomic impact of blindness is grave. In our society, there is virtually no employment for the visually disabled, so they suffer all the psychological and social consequences of lack of employment. Blind persons, particularly if they are aged, suffer social isolation and are dependent on others. They are subject to emotional distress with a two-fold risk of depression. The risk of falls and fractures are twice as high in the blind. In this case disability is not only about blindness or an inability to see far, it is also about inability to see close objects clearly or to read.

I would like to share with you something which was brought home to me very recently by a research study on the quality of life of older women who could not see close objects - a common occurrence in persons over the age of 40 years. For these women, it meant gradual marginalization and isolation from the mainstream of their lives as home keepers. Because they could not see close objects clearly, they could not detect those small things that are vital to personal hygiene and appearance, whether for themselves or their grandchildren, e.g. cutting finger nails to get rid of dirt beneath the nails, washing dirt off children's faces or bottoms, detecting the dirt in clothes. Lack of personnel hygiene contributes to the spread of disease. They could not recognize faces from a distance thus affecting social interaction which is so important in the African setting. They could not pick the stones from rice or the local cereals. They thus got excluded from preparing meals. Gradually their relevance in what they knew how to do best - being home makers - was eroded. And all because of the lack of a service which could test their eyes and provide a simple pair of glasses and a society which has failed to see that it is totally beneficial to see well with glasses than to be gradually marginalized from the daily activities of life.

Going back to Australia, the researchers did their arithmetic and calculated the three categories of cost - direct, indirect, and cost of suffering and premature death. What were the findings? 
The cost of suffering was almost $50 \%$, followed by lost income at $18 \%$, while the direct costs totalled $18 \%$. The total indirect costs were twice as high as the direct costs.

Three-quarters of the visual impairment was due to 5 conditions. Also, three-quarters of the visual impairment was unnecessary and prevention was often more cost effective than treatment, whether for cataract surgery, diabetic retina screening or laser therapy. The total cost was estimated at $\$ 9.85$ billion in 2004 . It was very clear that sight was a worthwhile investment and the timing of that investment was urgent!

Investing in sight would achieve the elimination of avoidable blindness and visual impairment and its impact through prevention, early detection and management, rehabilitation and research. The two questions the researchers sought to answer were:

1. What is the additional spending required?

2. Where might such spending be best directed?

\section{The Review Process}

What process did they go through?

1. They identified various interventions

2. They costed the interventions using different models considering:

a. the delivery mechanism

b. the compliance by the public, the patients and the provider

c. the effectiveness

d. the immediate and secondary costs and benefits

3. The cost of intervention was compared with the cost of no intervention, derived from the first study of the economic impact of cost of vision loss.

To bring this nearer home to Nigeria, using cataract as an example, the intervention here is surgery and implantation of intraocular lens. The models in Nigeria are:

- The event model - camps or the safari surgical team model

- The high volume centres model (usually mission hospitals)

- The training centre model (usually teaching hospitals)

We could apply the Australian process. In Nigeria, it is estimated that we would have to do 2000 cataract operations per million population to keep up with the new cataract cases per year. Currently, we are doing 300 cataract operations per million population per year. What is the economic impact and cost of vision loss for the 1700 cataract blind persons per million population who are still waiting for surgery and may die blind?

What would be the input, output, impact and benefit of each model? What would be the unit cost, i.e cost per cataract surgery for each model?
Can we use the Australian process and apply each model? Or should we use the object process to guide us in choosing which model to adopt? How do these models fit in with the NEPAD health strategy?

I had expected that the interventions identified by the Australian study would be high technology based and very specialized. On the contrary, Australia's strategies for investing in sight were simple, innovative, few and concise.

A public campaign was key; it was people targeted to ensure awareness. The aim was for people to participate in and accept prevention, allow detection of disease as early as possible, and accept responsibility for their own eye health. The second strategy was thinking outside the box - using innovative approaches to reduce cataract surgery waiting time, increase access to eyeglasses and increase access to remote populations. The third strategy was eye research and development; and finally, work force and training changes so vital for a campaign, and innovative service delivery mechanisms.

Most impressive is the fact that it was not 'rocket science'; these were simple actions. For awareness raising, detection and early intervention, activities proposed were:

- Eye examinations for the following:

- 5 yearly for $>40$ years of age

- 2 yearly for

- persons with a family history of glaucoma

- people with diabetes mellitus

- 75 years of age

- Campaign to stop tobacco smoking

- Protection from UV exposure - sunglasses campaign

- Prevention of eye injuries

- Low vision services

- Application of appropriate technology

The total cost of the package of interventions in 2005-6 was US $\$ 188.8$ million, with a positive financial benefit starting in 2006-7 at US\$1-2 million over the lifetime, a direct net financial savings of over $\$ 650$ million. The quality of life gains over the lifetime was even higher at US\$7.7 billion.

However, in Australia, it was recognized that the workforce constraint may be the single most important limiting factor to the successful implementation of the proposed and costed interventions. It would be useful to dwell a bit on investing in sight as it concerns human resources (work force) development. In Africa, I daresay in Nigeria, the lack of human resource is a major constraint and will be for some time. What I would like to address, therefore, is the issue of maximum utilization of existing human resources.

Competence measures what a person can do under ideal circumstances; our training institutions and professions prioritize and lay emphasis on competence, and so they should. Performance measures what a person does with existing resources. 
One of the constraints to maximizing the output of the workforce is the box phenomenon. This is an area which we really need to address. We need to move from the box phenomenon of individual professions to the formation and functioning of health teams in which each member recognizes the importance of the other in an ambience of mutual respect. In the Nigerian society, which is a structured hierarchal society - the team concept will be a challenge. To achieve the concept of the correct 'mix and match' of the members of a team, the art of delegation matched with the right degree and amount of supervision will need to be adopted. What makes a civil servant productive? Whatever his output, his salary is paid. There are no set targets of output. Moreover, output is not related to the needs in a population. Training and function should therefore change to address competence as well as performance and both should be driven primarily by the needs of the population and secondarily by provider-related perceptions.

An example of improving performance in one hospital is worth sharing. It is from the Aravind Eye Hospital in India, which has adapted business management principles and strategies to health delivery. Aravind carried out a study on how the performance of a surgical team could be increased in order to increase the number of cataract surgeries done, which would lead to a reduction in cataract blindness. This was to be done through a good mix and match of:

- Team members - surgeons, scrub nurses who assist the surgeons, and running nurses

- Infrastructure - operating tables

- Technology - cataract sets

Table 7. Increasing performance -the cataract output of a surgical team (Aravind Eye Hospital, India)

\begin{tabular}{lllllll}
$\begin{array}{l}\text { Surgeon } \\
\text { tables }\end{array}$ & $\begin{array}{l}\text { Operating } \\
\text { nurses }\end{array}$ & $\begin{array}{l}\text { Runnin } \\
\text { g nurses }\end{array}$ & $\begin{array}{l}\text { Instrum } \\
\text { ent sets }\end{array}$ & $\begin{array}{l}\text { Surgeri } \\
\text { es/hour }\end{array}$ & Scenario \\
\hline 1 & 1 & 1 & 1 & 1 & $1-2$ & A \\
1 & 1 & 1 & 1 & 3 & 3 & B \\
$1+1$ & 2 & 2 & 1 & 6 & 6 & C \\
\hline
\end{tabular}

You will notice that in scenario $\mathrm{C}$, with still one surgeon, an increase of one more operating table which could be made locally, one more scrub nurse whose training could be done on the job and 5 more cataract sets which could be purchased, they increased the number of surgeries from 1 to 6 per hour. In line with these changes which fit each other like a jigsaw puzzle, were the team work, a strong work ethic, and high performance systems which made the team function like a well-oiled machine or a factory belt. Underlying all of that was the fervent wish of all team members to score the goal of increasing their performance, of reducing blindness! Let us come nearer home to Africa.

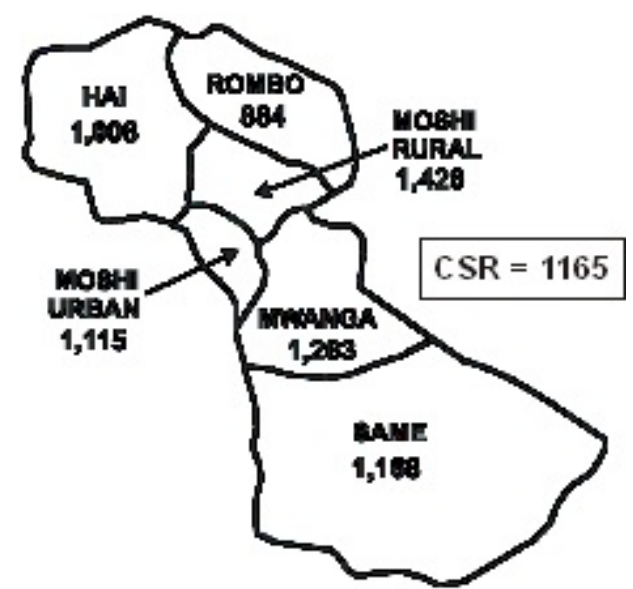

Figure 4. CSR by district, Kilimanjaro Region, Tanzania, 2004

The map shows the Kilimanjaro Region of Tanzania with a population of 1.4 million. In 2004, 1,165 cataract operations per 1 million population were performed in the region. This region is made up of 5 districts and each district almost uniformly benefited from the service. In Nigeria, if you take the average cataract surgery rate in a state, you may find that almost all the surgeries were performed on the population nearer the urban centre and most times by one centre (the mission centre usually); obviously a case in which neither equity of access nor performance has been addressed. What changes did the Kilimanjaro Region make in order to achieve uniform access and performance? The changes were made not just at the hospital but also at the community and the health levels between.

\begin{tabular}{|l|l|}
\hline \multicolumn{2}{|c|}{ What changes were made? } \\
\hline Hospital & Comm unity \\
\hline $\begin{array}{l}\text { Operating room efficiency } \\
\text { as Aravind }\end{array}$ & $\begin{array}{l}\text { Development of referral site } \\
\text { programme to increase access }\end{array}$ \\
\hline $\begin{array}{l}\text { Better management of } \\
\text { clinical personnel - having } \\
\text { the right number and mix }\end{array}$ & $\begin{array}{l}\text { Creation of team approach to } \\
\text { service delivery; horizontal } \\
\text { and vertical }\end{array}$ \\
\hline $\begin{array}{l}\text { Hiring of manager } \\
\text { Dedicated programme } \\
\text { manager and counsellor }\end{array}$ \\
\hline $\begin{array}{l}\text { Hiring of clerks for } \\
\text { registration and record } \\
\text { keeping }\end{array}$ & Defined roles of all partners \\
\hline
\end{tabular}

Two changes which must be highlighted are: the team concept and the inclusion of programme managers and counsellors as members of the team. To maximize the output of the surgeon, a manager is required to ensure that all the systems function efficiently and the technical members of the team have all they require to do the work. Health and vision is a product, our consumers are the patients and the public. We must have members of the team - counsellors - who at each point can spend time with the consumers explaining, addressing fears, and answering questions. We need to turn 
our hospitals from disease palaces which people dread, to health homes which people are delighted to visit.

It should also be noted that the service in the Kilimanjaro Region was a continuum from the hospital to the community. Each level recognized the interdependence of one on the other. Patients moved from one level to the other for supervision and support, ensuring quality, best practice and optimum performance.

On performance, in my interaction with ophthalmic surgeons in West Africa, I usually pose the question, and go through the arithmetic exercise below.

\section{How many cataracts can one surgical team do?}

- Assume one team operates 2 times a week

- Assume 10 cataract cases are operated in one surgical session

- This adds up to 20 cases per week!

- Assume one team works 40 weeks per year

- $20 \times 40=800$ cataract surgeries/year!

Without exception, each surgeon has assured me that even in Nigeria, it is very possible to achieve these figures. The Aravind and Kilimanjaro examples demonstrate that the surgeons and the team members worked smarter not harder.

The table (below) from WHO Prevention of Blindness Africa V2020 co-coordinator shows Nigeria's position in the cataract surgical rate league table. The CSR for Nigeria is about 300. The question is: Is this due to lack of surgical teams or low productivity? We find that Nigeria, with a productivity level of $\mathbf{1 6 0}$ cataract surgeries per surgical team per year, is even lower than most countries. Clearly performance by our work force is a major issue.

Robert Reich, a US economist and politician said:

Your most precious possession is not your financial assets. ... Your most precious possession are the people working there and what they carry around in their heads and hearts and their ability to work together

I would now like to take this issue into the wider arena of human resources for health and the international health agenda. In 2004, at the World Health Assembly, resolution WHA 57. 19 was passed on international migration of health personnel. The World Health Organization has made Human Resource for Health (HRH) the theme of the 2006 World Health Report.

There are many groups and initiatives on $\mathrm{HRH}$; they include the World Health Organization, the Joint Learning Initiative, the High Level Forum on the Health MDGs whose last meeting in December 2004 was held in Abuja, NEPAD, and the Commission for Africa. There appear to be a lot of movement initiatives on human resources for health; they should not end up as beautifully written documents, reports of consultants, meetings and workshops without translating into changes which will impact on the lives of Africans today.

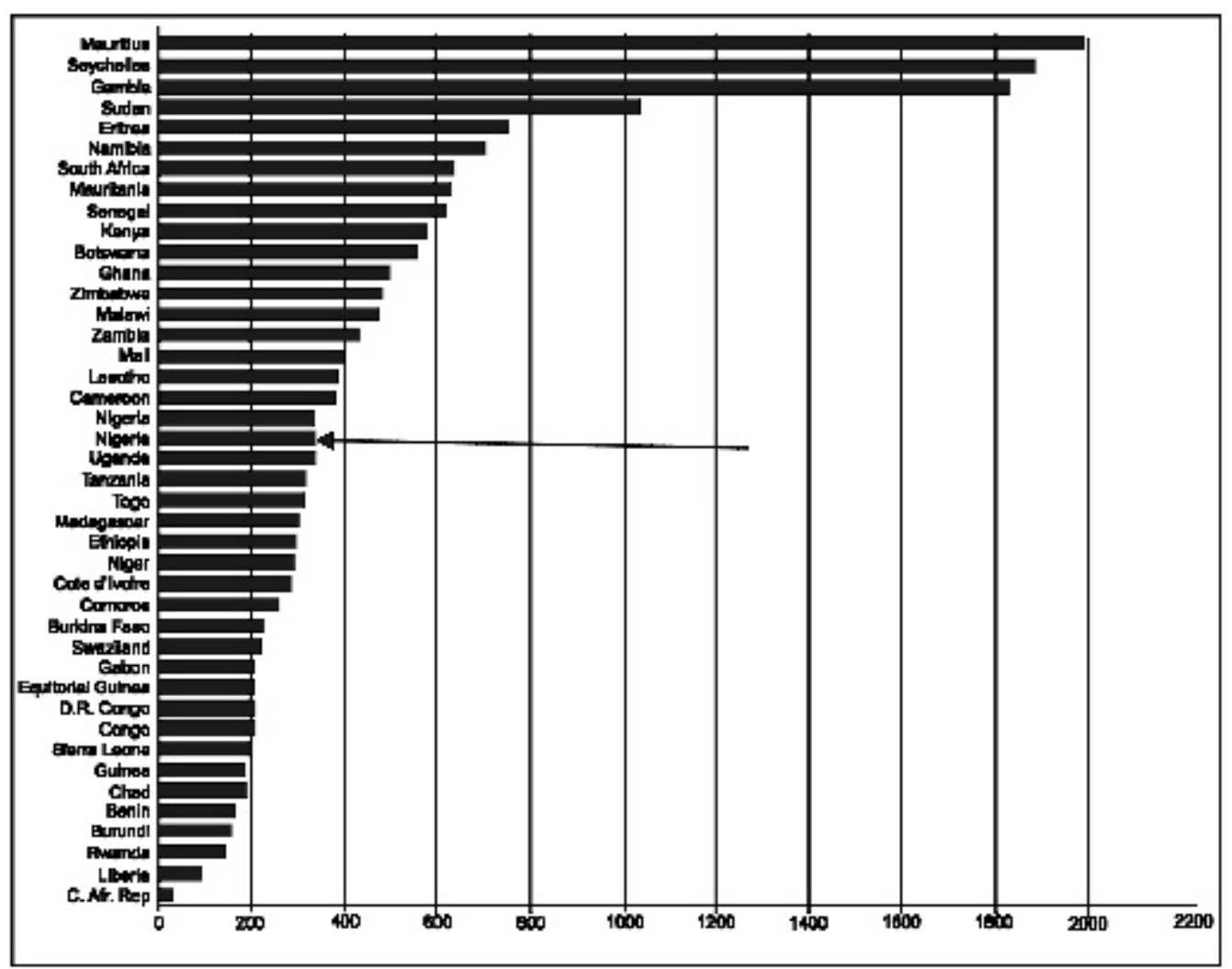

Figure 5. Cataract surgical rate in Africa by country. 
The change can only happen from within. "What people carry around in their heads and hearts and their ability to work together".

What are the economics of HRH? It is estimated that low- income countries subsidize high-income countries to the tune of US\$500 million a year through the movement of health workers. In developing an eye care programme, often one came across the term 'zero growth'. A post or a promotion was needed but the budget would not allow it because of 'zero growth'. What is the impact of the macroeconomic policy conditions imposed by the International Monetary Fund on human resources for health? How did countries get into the situation which led to these negative policies from the IMF?

What can Nigeria do with its existing resources? Can we explore an economic analysis of our current status, our distribution of personnel, the use of middle-level workers and the use of teams?

I would like to illustrate my next point with 3 wheels, of different sizes, each fitting within the other to ensure movement; the three wheels represent human resources; infrastructure and technology; and principles, systems and protocols.

We have explored the first wheel which is human resources. The next investment to address is technology. For human resources to be maximally productive, they need facilities and technology to work with. To get the maximum return on investment, there needs to be, not only the correct mix and match, but accurate sequencing in provision. If a person finishes training before the facility and or technology is ready or vice versa, there is a loss on investment. Or, if the technology is too advanced for the competence of the human resource there would also be a loss on investment.

The economics of technology lies in the initial cost, its maintenance and repair, and its utilization. It is estimated that at least $50 \%$ of the technology equipment in health facilities are not functioning. To have a maximum return on investment in technology, the following ideas may need to be considered:

- Prioritization of expenditure - categorizing equipment by the number of stars: three stars for 'must have', two stars for 'useful to have', one star for 'nice to have' based on the needs of patients more than the wishes of the providers.

Economic analysis on equipment utilization and

economic return on investments - how many patients benefit and how many hours a day is a piece of equipment in use?

- Calculations of equipment idling time - for how long

does an equipment remain non-functional because of lack of repair or maintenance, and what is the opportunity cost? For every building and technology, what budget is put aside for repair and maintenance to reduce idling time to the barest minimum?
- What is the damage cost of cutting corners, diverting funds from a building or an equipment? What is the economic cost of not building to the best standards in repairs and maintenance? Where the funds divert to personal gain, what is the economic cost to the overall development of the population? Much of what we do is short term gain for long term loss.

Some ways in which we could consider investing in sight is the pooling of services and technology within and between the public and the private sector. Each facility does not have to have every expensive technology. Systems could be put in place to ensure one institution with one technology provides the service to a cluster of other institutions with an agreed systems of economic investment and returns.

A system of standardization and the use of standard lists of technology could provide the advantages of bulk purchase and economy of scale, availability of spares, and ease of repair and maintenance. VISION 2020 - The Right to Sight Technology Working Group is providing guidance on this for eye care programmes at the district level.

Much of technology for sight still needs to be imported, be they equipment or drugs, dressings or consumables. The government raises revenue from importation. How much does it lose from the economic impact of lack of service delivery for lack of the necessary technology? Can the government carry out research into the economics of cutting out the middleman and the false economy of duties and taxes? The government of India led the way in this respect when decades ago it prioritized and made importation of technology, drugs, etc for its national eye care programme duty free and encouraged industry to produce locally. Today, India is exporting and its blindness control programme is a model for other countries.

The third wheel is the way things are done - systems, protocols and procedures. Two examples illustrate this point. In going round countries and working with them to set up eye care programmes, I constantly dialogue with eye care providers. Usually the first constraint to poor services identified by the providers in government institutions is lack of training; the staff need to go for one course or the other so they are sent on the course. The next reason is that they do not have specific items to do the work and this is also provided. Productivity still remains low. Another constraint identified is that the patients cannot afford the cost of service. Then it turns out that another hospital 30 minutes away from the government hospital is full of patients and the government hospital is empty and very little surgery is done.

The staff then run out of constraints because usually the busy hospital is more expensive for patients. Finally, the real constraint is identified, that busy service delivery depends on demand generation by building a reputation for quality, reliability, credibility and compassion. A government institution can and must build such a reputation as part of its reason for existence. 
Another example is to look at the issues of market, cost and the product, using the example of the matches trade. Matches can be sold in boxes of 12 or 6 , as single boxes or, in poor areas, in bundles of matchsticks. The product is presented and provided to suit the ability of the customer to pay. The madam who sells breaks up the product into smaller units and gives it to younger less experienced persons (delegation) who cry out their wares (positive campaign) move around (increase access for their customers) and delight and attract the customer to buy the matches. Intermittently, the madam checks on the young sales persons (supervision). At the end of the day the remaining matches are counted (stock management), the money made is calculated (revenue management), a report is made to madam (reporting), hard work, transparency and accountability is rewarded. The profit made is re-invested to ensure growth and expansion. For the truly successful business, the workers buy or have shares in the business and a true team concept is enshrined.

Sight is a product, indeed a highly desired product. It needs to have the business principles, systems and protocols which will make it as ubiquitously available as a bottle of soft drink, so said Dr. Venkataswamy of the famous Aravind Hospital.

Vision as a product can generate income from service rendered, training and materials and such income can then be used to subsidize services to the poor to ensure equity.

Going back to the millennium development goals and the three goals dealing directly with health, the diseases mentioned and prioritized lead to death. But it is increasingly being recognized that disease, disability and death are inextricably linked.

Disability is any restriction or lack of ability to perform an activity in the manner or within the range considered normal for a human being; it leads to loss of well being, suffering and premature death.

James D. Wolferson, former president of the World Bank stated:

Unless disabled people are brought into the development mainstream, it will be impossible to cut poverty by half by $2015 \ldots$

In this context, visual disability relates to the MDGs because of the cause and consequence relationship between poverty and any disability, but much more so for visual disability. Like poverty, the highest figures for disability occur in developing countries.

Basically disability is a difference from the 'normal'.

- We are for difference

- For allowing difference

- For learning to understand difference

- For respecting difference

- Until different does not make any difference

This applies just as much to disability.

We should be for our disabled

- For allowing disability
- For learning to understand disability

- For respecting the disabled

- Until their disability does not make any difference in how we relate to them

- We change in order to include them amongst us In Nigeria, we emphasize difference - state, LGA, tribe,

language, professional institution, etc. These thoughts could apply just as well to these things.

Globally, a child goes blind every minute, an adult every second. The disabled make up $15-20 \%$ of the poor. They have lower levels of school attendance and performance. They suffer marginalization and social exclusion. There is a clear relationship between disability and chronic poverty.

Visual disability is a major component of disabilities and has a major impact on the quality of life. It has been proven in other countries that it is much cheaper, more rewarding and highly beneficial to enhance residual vision, rehabilitate the blind and educate the blind child. Cost benefit studies need to be done in Nigeria to assess the impact without and with rehabilitation and education and to assess communitybased rehabilitation and integrated education against traditional seclusion in schools for the blind. Only in practicing social inclusion and rehabilitation can one break the cycle of poverty into which the visually disabled are forced.

Earlier on, I introduced VISION 2020: The right to sight - a global vision of the International Agency for the Prevention of Blindness (IAPB) and the World Health Organization. This emanated from IAPB asking itself the question, Quo Vadis? It had vision but what else did it need to do? It recognized that vision had a much wider stakeholder base than just the medical group. It looked at the economic case for its vision through research and publication in order to bring in the economic minds of the world as stakeholders in vision. It appreciated the crucial role of technology and thus the need to include the corporate sector not just for their social responsibility but also as they are the constituency for the technology component for Vision 2020: The right to sight. The same case applied to the media and the campaign for the public ownership of the vision. The International Agency for the Prevention of Blindness reviewed its mission statement to recognize its links to the irreversibly visually disabled. It is hoped that soon the message on vision will go out in one voice from promotion through to education and rehabilitation of the irreversibly visually disabled.

At the beginning of this lecture, I mentioned the reasons why I chose the topic - essentially 'dreams', funding issues, the Millennium Development Goals, poverty reduction, health and development, Africa and its partnerships. As George Bernard Shaw said:

You see things and say "Why"? But I dream things that

never were, and say "Why not!"

So I say: Nigeria - Why Not? Health Workers - Why Not? 


\section{AGENTS OF DEVELOPMENT}

Quo Vadis - Nigeria? Quo Vadis - Ophthalmological Society of Nigeria? As Peter Serge once said:

The origin of the vision is much less important than the process whereby it comes to be shared. It is not truly a shared vision until it connects with the personal vision of people throughout the organization.

John Harvey Jones also said:

Organizations only change when the people in them change, and people will only change when they accept in their hearts that change must occur.

This morning when I was leaving for the lecture, the passage for the day in my little book was from Proverbs 29 v 18:

Where there is no vision, the people perish ...?

I want to thank my ophthalmology colleagues who have worked so hard to prepare for this event, especially those in the Department of Ophthalmology, UCH, Ibadan, as well as colleagues and friends who have travelled long distances to attend this lecture.

I specially want to thank Professor Laitan Soyanwo, a dear friend who has always been a home away from home for me in Ibadan. God bless you all

God bless Nigeria and the National Post Graduate Medical College of Nigeria.

\section{REFERENCES}

Cost Benefit Analysis of the Gambian Eye Care Programme. Personal communication.

Faal H. National Surveys of Blindness and Low Vision in the Gambia, 1986 and 1996.

Frick KD, Foster A. The magnitude and cost of global blindness: An increasing problem that can be alleviated. American Journal of Ophthalmology 2003; 135: 471-6.

Investing in Sight-Strategic Interventions to Prevent Vision Loss in Australia- Report prepared by Access Economics Pty Limited

Javitt JC. The cost-effectiveness of restoring sight. Archives of Ophthalmology 1993; 111: 1615.

Make Development Inclusive. Light for the World. 2009.

Make Poverty History Campaign.

Millennium Development Goals and Disability. SourcesUNDFID, UN Centre for Human Rights, UN Population Fund, UNICEF, World Bank, WHO, Water Aid.

NEPAD Health Strategy, September 2003

Sachs J. Doing the sums on Africa. The Economist May 22, 2004.

The Economic Impact and Cost of Vision Economics. Pty Limited.

World Bank. 1977. Economic Impact of Onchocerciasis through APOC. World Bank Report.

World Health Assembly Resolution on Disability - WHA 58.23 . 